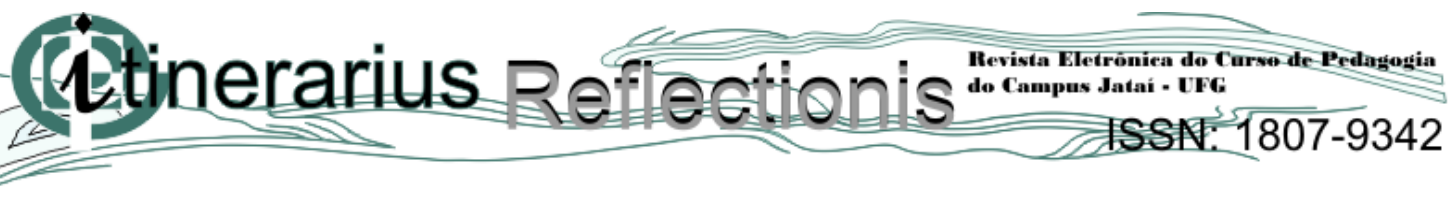

\title{
O USO DE MODELAGEM MATEMÁTICA NO ENSINO DE FUNÇÕES NAS SÉRIES FINAIS DO ENSINO FUNDAMENTAL: UM ESTUDO DE CASO
} Elenilson de Vargas Fortes Instituto Federal de Educação, Ciência e
Tecnologia de Goiás. vargasfortes@ yahoo.com.br

Airton Wagner de Souza Junior Instituto Federal de Educação, Ciência e Tecnologia de Goiás. airtonwagner@gmail.com

Ana Maria Libório de Oliveira Instituto Federal de Educação, Ciência e Tecnologia de Goiás. analiborio@gmail.com

RESUMO: No presente trabalho apresenta-se uma proposta de aplicação da técnica Modelagem Matemática para o Ensino Fundamental, especificadamente no $9^{\circ}$ ano, onde o principal objetivo foi discutir aplicações de funções. Destacaram-se por meio deste artigo, alternativas para o ensino-aprendizagem de funções, no qual se estimulou o aluno a formular e analisar seus próprios modelos matemáticos obtidos por meio de um estudo de caso. Para utilizar esta técnica, trabalhou-se o tema reciclagem, de forma interdisciplinar, com as aulas de Geografia. Esta escolha, como será prontamente discutida em seções futuras deste trabalho, não foi por acaso e tornou-se ferramenta fundamental para se trabalhar o conteúdo de funções por intermédio da modelagem matemática. Mostrou-se através desta pesquisa, por meio da modelagem, que a aulas de matemática tornaram-se mais produtivas, aumentou o interesse dos alunos pela matemática e, por fim, os alunos envolvidos nesta pesquisa vivenciaram a importância da matemática escolar no que tange ao conteúdo de funções através da modelagem matemática. Além disso, foi possível observar significativas mudanças no processo de ensino e aprendizagem nesta série do ensino fundamental através de alterações na prática pedagógica docente, pois houve melhoras significativas nas médias dos alunos envolvidos na pesquisa.

Palavras-Chave: Modelagem matemática, Funções, Educação Matemática, Reciclagem.

ABSTRACT: In this paper it is presented a proposal for the application of mathematical modeling technique for Elementary Education, specifically in 9th grade, where the main objective was to discuss applications of functions. It is highlighted through this article, alternatives for teaching-learning functions, in which the student is encouraged to formulate and analyze their own models, obtained by means of a case study. To use this technique, we worked up the recycling theme, in an interdisciplinary way, with the lessons of Geography. This choice, as will be readily discussed in later sections of this work, it was no accident and became a fundamental tool to work with the contents of functions by means of mathematical modeling. Proved through this research, through modeling, the math classes have become more productive, increased students' interest in mathematics and, finally, the students involved in this study experienced the importance of mathematics in relation to content functions through mathematical modeling. In addition, we observed significant changes in the process of teaching and learning at this grade education through changes in teaching practice, 


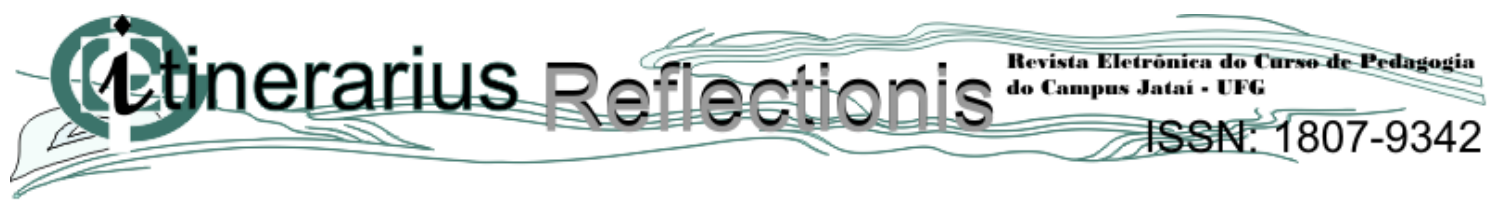

as there was significant improvement in the mean of the students involved in the research.

Keywords: mathematical modeling, Functions, Mathematics Education, Recycling.

\section{INTRODUÇÃO}

A matemática há tempos é considerada uma ciência que auxilia o homem a facilitar e organizar o meio onde estamos inseridos. Além disso, é amplamente utilizada com a finalidade de encontrar soluções para problemas práticos do cotidiano. Suas aplicações estão presentes em várias áreas de conhecimentos, como Física, Química, Biologia e outras. Porém, ainda assim, muitos de nossos alunos não estão familiarizados com tais aplicações. Não é difícil, por exemplo, ouvir dos discentes a seguintes frases: "Professor, para que serve isto ou aquilo? Vai ter utilidade na minha vida? Vou aplicar aonde?". Certamente, ouvir tais questionamentos destes ao professor, é desafiador, pois nem sempre se tem uma resposta adequada para o momento dos questionamentos, afinal muitas aplicações para determinados conteúdos matemáticos só são vistos e analisados por pesquisadores, no mestrado ou no doutorado.

Diante do exposto, cabe aos educadores, encontrar caminhos de forma arrolar argumentos significativos na tentativa de encontrar respostas a estes questionamentos. Seguindo esta linha de raciocínio, este trabalho mostra uma alternativa interessante a esses problemas corriqueiros no ensino de matemática. Trata-se da utilização da Modelagem Matemática no contexto escolar. A ideia de utilização da Modelagem da Matemática é relativamente simples. Parte-se de um tema vivido na sociedade, aproveita-se o conhecimento empírico dos alunos sobre determinado assunto e mostram-se aplicações práticas de algum conteúdo da matemática, com objetivo, de facilitar o entendimento dos alunos sobre tal assunto.

Atualmente, a modelagem matemática tem sido um tema bastante debatido entre os pesquisadores da área, dentre eles, pode-se citar, Bassanezi (2010) e Biembengut \& Hein (2010), todos com ideias de relacionar conteúdos escolares com problemas reais. Mas, o que é modelagem matemática? Não há uma definição singular do que seja modelagem matemática e isto é perceptível na fala de professores e pesquisadores sobre esse tema. Investigações a respeito indicam que há de fato várias linhas de pesquisa sobre o assunto. A maior parte, entretanto, caracteriza o modelo como algo que descreve o problema em termos reais, sua 


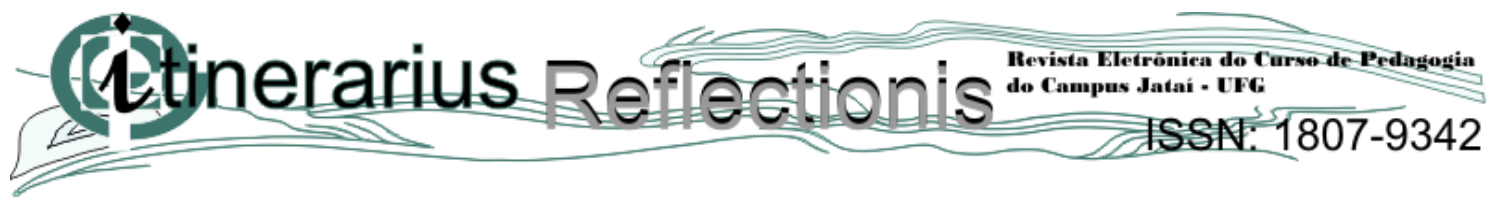

resolução é analisada, organiza em informações matemáticas e retorna novamente ao problema inicial.

Mas, por que utilizar modelagem matemática como metodologia de ensino? Para Menezes (2007, p. 35) “as crianças são curiosas por natureza, mas só aprendem se tiverem espaço para participação. E isso só existe quando há conversa, fala e argumentação e não um ambiente de apatia". Portanto, o educador deve proporcionar um ambiente adequado na sala de aula, e de certa forma, procurar alterar a maneira de expor os conteúdos que na maioria das vezes são expostos de forma repetitiva e tradicional, sempre procurando atrair a atenção dos alunos, incentivar a pesquisa e gerar questionamentos. Na prática, em sala de aula, o educador da disciplina de matemática precisa criar metodologias diversificadas para conseguir melhorar a qualidade do ensino e que sejam satisfatórias para sua realidade. "Neste sentido, a modelagem, arte de modelar, é um processo que emerge da própria razão e participa da nossa vida como forma de constituição e de expressão do conhecimento" (Biembengut \& Hein, 2010, p.11). Neste artigo, como será demonstrado a seguir, pretendeu-se colaborar com este propósito, isto é, trabalhar o ensino de matemática com o auxílio da modelagem matemática.

Nas palavras de Biembengut \& Hein (2010, p. 9) “a matemática é o alicerce de quase todas as áreas do conhecimento e permite desenvolver os níveis cognitivos e criativos, nos diversos graus de escolaridade", isto é, a matemática é uma disciplina que consegue instigar habilidades nos alunos, tornar um ser inventivo, através de resolução de problemas. Para resolver tais problemas tem-se que investigar todos os fatos que o envolvem. Pólya? (1995) destaca quatro passos para melhor compreensão de problemas. São eles: "Compreensão do problema", "Estabelecimento do plano de resolução", "Execução do plano" e o "Retrospecto".

No que tange a "Compreensão do problema", Pólia? (1995, p. 04) destaca que o aluno além de compreender o problema, este "deve também desejar resolvê-lo [...]. O problema deve ser bem escolhido, nem muito difícil nem muito fácil, natural e interessante, e um certo tempo ser dedicado à sua apresentação natural e interessante".

Em relação ao "Estabelecimento do plano de resolução", Pólia (1995, p. 05-06) afirma que não é uma técnica específica no "estabelecimento de um plano" para resolução de determinado problema. Este depende obviamente de cada problema proposto. Este assegura, por exemplo, que uma “ideia pode surgir gradualmente ou, então, após tentativas infrutíferas e 


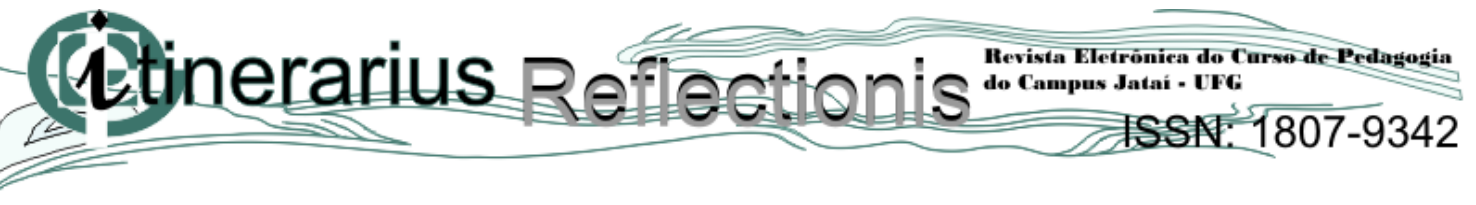

um período de hesitação, aparecer repentinamente, um lampejo, como uma ideia brilhante", (PÓLIA, 1995, p. 05).

A “Execução do plano”, segundo Pólia (1995, p. 08), não é uma tarefa fácil. Afinal, o aluno "para conseguir isto é preciso, além de conhecimentos anteriores, de bons hábitos mentais e de concentração no objetivo, mais uma coisa: boa sorte. Executar o plano é muito mais fácil; paciência é o de que mais se precisa", (PÓLIA, 1995, p. 08).

Por fim, Pólia (1995, p. 10) descreve sobre o "Retrospecto". O autor afirma que para melhor fixação do problema que por ventura for resolvido, este antes de dar prosseguimento à próxima atividade, deve fazer um "retrospecto da resolução completa, reconsiderando e examinando o resultado final e o caminho que levou até este, eles poderão consolidar o seu conhecimento e aperfeiçoar a sua capacidade de resolver problemas", (PÓLIA, 1995, p. 10).

Neste trabalho, como será apresentado doravante, escolheu-se o conteúdo de funções como principal ferramenta para modelar um problema corriqueiro vivenciado pelos alunos engendrados nesta pesquisa. Esta escolha não foi aleatória e como será demonstrado em seções futuras, este é um conteúdo matemático que possui amplas aplicações em diversas áreas do conhecimento, como na química, física, biologia e outras. Aparece sempre quando se relaciona duas grandezas, isto é, uma variável depende da outra. Seu conceito é um dos mais importantes da matemática. É considerada excelente ferramenta para solucionar e representar questões atuais, podendo simular graficamente uma situação problema. Nesse sentido, a modelagem pode ser usada para desenvolver o raciocínio lógico e tornar-se uma metodologia alternativa e eficiente para o aprendizado de matemática, neste caso em particular, ensino e aprendizagem de funções.

O tema escolhido para correlacionar com a matemática e criar um modelo matemático foi a Reciclagem, especificadamente o lixo. A escolha deste tema não foi ocasional e alguns critérios foram utilizados, contudo se adia temporariamente a discussão acerca deste assunto, no qual será prontamente discutido na seção Escolha de um Tema para Aplicação de Modelagem Matemática e Funções.

O procedimento utilizado para o estudo da técnica proposta neste trabalho foi o Estudo de Caso. Trata-se de um "estudo empírico que investiga um fenômeno atual dentro do seu contexto da realidade", (Gil, 1999, p. 72). Em particular, nesta pesquisa, pretendeu-se adotar um método para ensinar funções, distinto dos métodos tradicionais, por meio da técnica 


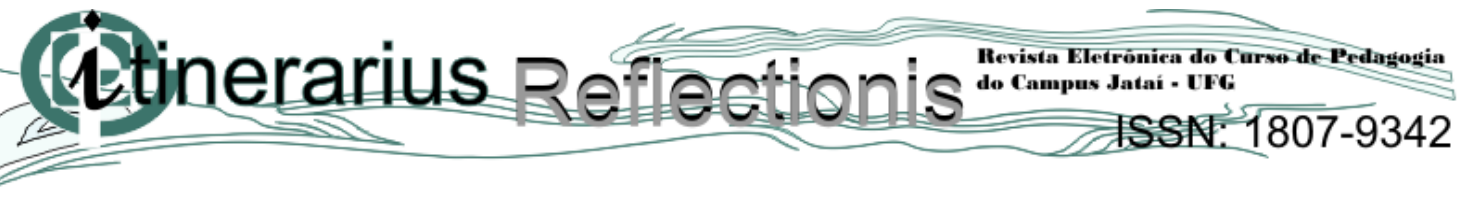

de modelagem matemática afim de que se possa, por meio do Estudo de Caso, "contribuir para a compreensão global de um certo fenômeno de interesse”, (PONTE, 2006, p. 02).

Este artigo, a partir da próxima seção, está disposto da seguinte forma: primeiro, descreve-se sobre a Modelagem Matemática como uma tendência de ensino. Relata-se, nesta seção, alguns conceitos sobre Modelagem Matemática e as etapas para construção de um modelo e sua utilização como uma das vertentes das linhas do Ensino da Matemática. Na seção, A formação do professor versus modelagem matemática, comenta-se sobre a formação do professor e a necessidade de incluir no currículo do ensino superior de licenciaturas, disciplinas que tratam especificamente da Modelagem Matemática. Na seção, Escolha de um Tema para Aplicação de Modelagem Matemática e Funções, justificam-se os motivos que levaram a escolha da reciclagem do lixo e funções como tema para aplicação da Modelagem Matemática no ensino de funções. Na seção, Justificativa da Escolha da Turma, descreve - se em detalhes o que justificou a escolha da turma do $9^{\circ}$ ano para aplicação da técnica Modelagem matemática no ensino de funções. Na seção, Situações Problemas, mostram-se alguns problemas práticos que foram abordados com os alunos envolvidos nesta pesquisa. Por fim, destacam-se os principais resultados obtidos por meio desta pesquisa através de gráficos.

\section{A MODELAGEM MATEMÁTICA COMO METODOLOGIA DE ENSINO}

Ensinamos demais e os alunos aprendem de menos e cada vez menos! Aprendem menos porque os assuntos são cada vez mais desinteressantes mais desligados da realidade dos fatos e dos objetivos mais distantes da realidade da vida dos adolescentes, (WERNECK, 1987, p. 13).

Começa-se esta seção com a citação de Werneck (1987), por entender que um educador precisa de empenho e dedicação para tornar suas aulas mais atraentes? em prol de alcançar outros objetivos como, por exemplo, estimular a cidadania, tornar o aluno mais crítico ou simplesmente saber fazer aplicações de determinado conteúdo em situações corriqueiras. Vive-se em uma sociedade tecnológica e globalizada, que tem sua força na informação, capaz de transformar rapidamente um conhecimento atualizado em um conhecimento obsoleto. Como consequências, entende-se que, mais importante do que transmitir informações e conteúdos para serem reproduzidos quando solicitados, é desenvolver nos educando habilidades e estratégias que lhes permitam de forma autônoma gerar novos conhecimentos. Para desenvolver nos alunos tais habilidades, faz-se necessário investir em metodologias que os habituem a utilizarem conhecimentos prévios, na perspectiva 


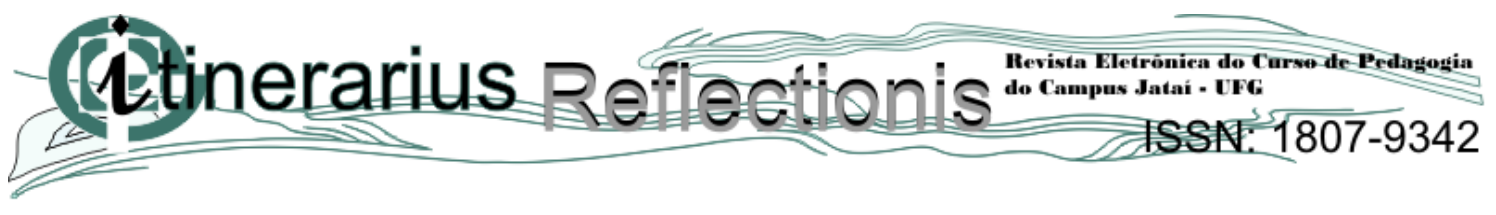

que encontrem em si mesmos, respostas às perguntas que os inquietam ou que precisem ser respondidas. Nesta concepção, a Modelagem Matemática pode ser utilizada como uma alternativa no processo ensino-aprendizagem de matemática.

A Modelagem Matemática, de acordo com Biembengut \& Hein (2010), pode ser definida informalmente como um escultor que precisa esculpir uma imagem. Este precisa de argila para produzir certo objeto. Esse artefato é um modelo. O escultor precisa estar munido de material, isto é, argila, técnica, intuição e criatividade para esculpir seu modelo, que de certa forma representa algo, real ou imaginária. Formalmente, Bassanezi (2010, p. 20) define modelo matemático "como um conjunto de símbolos e relações matemáticas que representam de alguma forma o objeto estudado". Por outro lado, este ainda afirma que o modelador ainda "precisa ter uma dose significativa de intuição e criatividade para interpretar o contexto, saber discernir que o conteúdo matemático melhor se adapta e também ter senso lúdico para jogar com as variáveis envolvidas”, (BIEMBENGUT \& HEIN, 2010, p.12).

Diante do exposto, é fácil de verificar que muitas circunstâncias do cotidiano representam situações que são necessárias soluções e decisões. Alguns desses problemas que contêm fatos matemáticos simples como, por exemplo, “O tempo necessário para percorrer uma distância de quarenta quilômetros, mantendo-se a velocidade a uma média de oitenta quilômetros por hora; O juro cobrado por uma instituição financeira a um determinando empréstimo; A área de um terreno de forma retangular", (BIEMBENGUT \& HEIN, 2010, p. 11). Além disso,

um modelo pode ser formulado em termos familiares, utilizando-se expressões numéricas ou fórmulas, diagramas, gráficos ou representações geométricas, equações algébricas, tabelas programas computacionais, dentre outros. Por outro lado, quando se propõe um modelo, ele pode ser proveniente de aproximações, nem sempre realizadas, podendo explicar melhor um fenômeno, e tais aproximações nem sempre condizem com a realidade, (BIEMBENGUT, 2010, p. 12).

De qualquer forma, um modelo matemático ilustra, ainda que em uma visão simplificada, aspectos de uma determinada situação pesquisada. Dentro dessa mesma linha de raciocínio, Bienbengut \& Hein (2010, p. 13) afirmam que uma forma de transformar uma situação vivida no cotidiano, isto é, uma situação real, num "modelo matemático" são necessárias três etapas fundamentais, sendo cada uma dessas etapas subdividida em outras duas subetapas. São elas:

1) Interação:

- Reconhecimento da situação-problema;

- Familiarização com o assunto a ser modelado referencial teórico.

2) Matematização: 


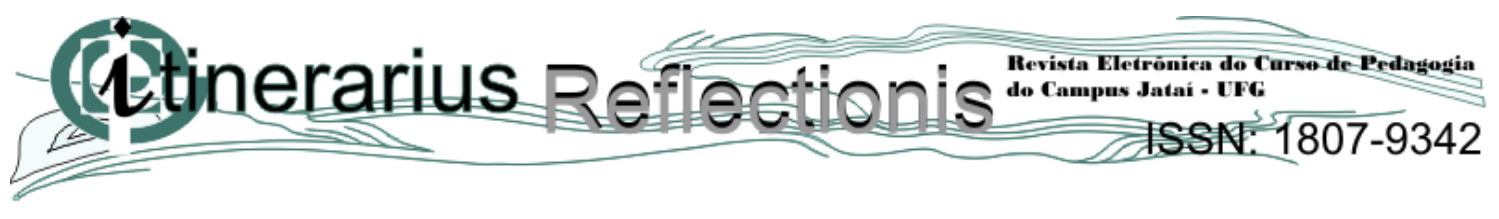

- Formalização do problema;

- Resolução do problema em termos do modelo

3) Modelo Matemático:

- Interpretação da solução;

- Validação do modelo.

Mas, o que é "iteração"? Esboçada uma determinada situação que se anseia explorar deve-se fazer uma pesquisa sobre o assunto de maneira direta ou indireta, em revistas, livros ou em dados experimentais. Não há necessidade de se obedecer a uma ordem rigorosa a fim de se alcançar a etapa seguinte, porém, deve-se frisar que quanto mais se estudar nesta etapa, isto é, houver interação com os dados, a situação problema tornar-se mais clara e acessível.

A "matematização" é a etapa mais implexa dentre todas. É uma etapa crucial do modelo matemático. Nesta etapa se traduz o problema para a linguagem matemática. Nesta fase, o modelador deve ter paciência, fazer uso de toda linguagem matemática que possui, ser criativo e, além disso, fazer uso de toda a sua experiência matemática acumulada afim de que se possa "matematizar" a situação-problema proposta. Estes são pontos imprescindíveis na construção deste processo.

A última etapa sugerida por Biembengut e Hein (2010) são os "Modelos Matemáticos”. Nesta etapa, devem-se analisar as conclusões do modelo, isto é, quais implicações têm a solução procedida daquilo que está sendo estudado. Verifica-se sua adaptabilidade, regressando à situação-problema pesquisada e ponderando quão expressiva e proeminente é a solução e sua validação. Deve-se ficar atento, pois se o modelo não acolher às necessidades que a originou, $\mathrm{o}$ procedimento deve ser recomeçado na etapa "matematização" fazendo os ajustes necessários para se conseguir os resultados ambicionados.

Diante do exposto, deve-se questionar se a modelagem inserida do ambiente de aprendizagem instiga a investigar outras áreas do conhecimento por intermédio da matemática. Na visão de alguns pesquisadores, sim.

Modelagem é um ambiente de aprendizagem no qual os alunos são convidados a
indagar e/ou investigar, por meio da matemática, situações oriundas de outras áreas
do conhecimento. Se tomarmos modelagem de um ponto de vista sócio-crítico, a
indagação ultrapassa a formulação ou compreensão de um problema, integrando os
conhecimentos de matemática, de modelagem e reflexivo, (BARBOSA, 2002, p. 06).

Portanto, a modelagem matemática vai além dos limites matemáticos, havendo de fato 'interdisciplinarização' de outras áreas do conhecimento. Por outro lado, educadores e 


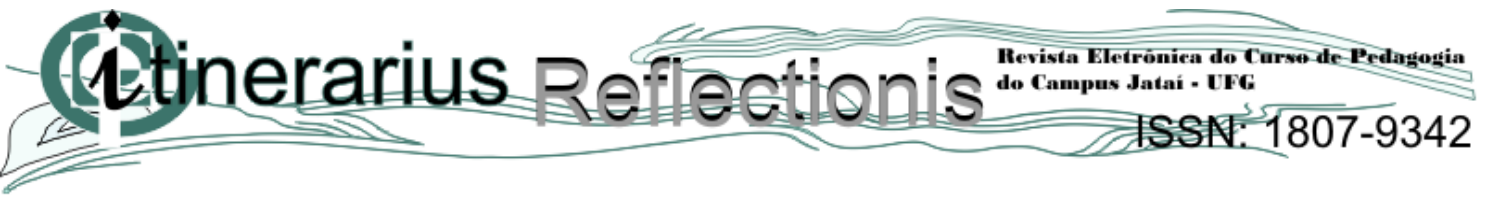

alunos devem ficar atentos, pois segundo Silva \& Jafelice (2005, p. 255), “É importante saber que a elaboração de um modelo depende do conhecimento matemático que se tem. Se o conhecimento matemático restringe-se a uma matemática elementar, como aritmética e/ou medidas, o modelo pode ficar delimitado a esses conceitos". Portanto, se educador e o educando tiverem déficit na matemática elementar necessária para desenvolver o modelo, este consequentemente ficará impossibilitado de desenvolvê-lo.

O professor de matemática deve ficar atento que a modelagem matemática deve ser utilizada como um método alternativo facilitando ao educando uma melhor compreensão da teoria no ensino de Matemática e que este procedimento não deve ser o a ser seguido, porém pode ser utilizado tanto nos cursos superiores, no ensino fundamental ou no ensino médio. Desta forma, o professor como mediador da informação deve sempre buscar a metodologia 'ideal' de ensino em cada caso específico e traçar um

\footnotetext{
um paralelo entre o ensino tradicional e o ensino através deste método, observando sempre pedagogia adotada, a criatividade, o interesse pelo estudo de Matemática, a motivação e entusiasmo por parte dos alunos e a avaliação do que eles realmente aprenderam com a Modelagem Matemática, levando o professor a refletir sobre a sua metodologia de ensino da matemática, (SILVEIRA \& RIBAS, 2004, p. 02).
}

Portanto, deve-se averiguar se a metodologia ou técnica empregada no ensino de matemática, que difere do ensino tradicional, empregada com o intuito de melhorar o ensino e aprendizagem do aluno, realmente causa o efeito esperado, seja ela através de avaliações ou de qualquer outra forma que se possa traçar um paralelo entre o ensino tradicional e o novo método utilizado.

\section{A FORMAÇÃO DO PROFESSOR VERSUS MODELAGEM MATEMÁTICA}

Certamente, há uma grande dificuldade para os professores de matemática se adaptarem a nova proposta de trabalho envolvendo modelagem matemática, porém esse déficit didático, em sua maioria, não é culpa do educador. Há de se questionar, por exemplo, no que tange a formação dos nossos professores de matemática, os seguintes questionamentos: será que os professores na Licenciatura em Matemática tem (ou tiveram) a oportunidade de trabalhar com modelagem em seus respectivos cursos? Será que um professor com déficit neste quesito pode ensinar com o auxílio da modelagem matemática? Certamente não, pelo menos não com toda potencialidade que poderia. Bassanezi (2010, p. 180) indaga que "o que o professor do ensino fundamental e médio deve conhecer para ser um bom professor de matemática?" 


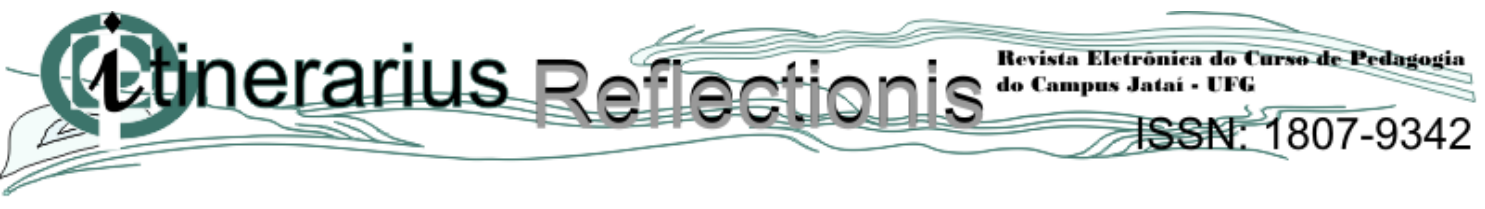

Em busca de respostas aos questionamentos acima, Bassanezi (2010, p. 180) faz um relato afirmando que no sul do país essa situação está se modificando com iniciativa do Governo do Paraná. Estabeleceu-se uma parceria entre professores da Universidade Estadual do Paraná com intuito de "organizar", um programa básico que deverá ser “articulado/discutido em todos os cursos de Licenciatura em Matemática do Estado". Este ainda sugere

que as sociedades cientificas e educacionais brasileira, SBEM, SBMAC, SBM, SBPC, e outras, iniciem, num esforço conjunto, discussões nesta direção, e visem a formação do professor de matemática, frente às transformações em processo no campo da Ciência, numa relação mais orgânica com as exigências emergentes do social e do econômico em termos globais, (BASSANEZI, 2010, p. 180).

Além disso, Oliveira (2007, p. 03) descreve sobre a importância da "inserção da Modelagem nos cursos de licenciatura em Matemática". Este afirma que esta inclusão deve ocorrer "por meio de disciplina específica ou em outras disciplinas do currículo, com o intuito de viabilizar aos futuros professores experiências e perspectivas em relação ao uso da Modelagem Matemática em sua futura prática profissional”. Portanto, as Universidades necessitam criar disciplinas que envolvam modelagem em sua matriz curricular a fim de suprir essas demandas dos profissionais da educação.

Como ainda são poucas as Universidades que oferecem em sua matriz curricular disciplinas que envolvem Modelagem Matemática, não há, portanto, como realizar um estudo detalhado no sentido de afirmar com precisão detalhes acerca da qualidade dos cursos que ofertam estas. O que se pode afirmar, embora não documentado aparentemente no meio acadêmico, é que alguns cursos de formação continuada incluem em seus currículos, algumas disciplinas que envolvam a modelagem matemática. A título de ilustração, como exemplo de inserção da disciplina de Modelagem Matemática nos cursos de graduação, pode-se citar o Curso de Licenciatura em Matemática da Universidade Tecnológica do Paraná ${ }^{1}$. Observa-se neste caso que as disciplinas "Modelagem Matemática 1" e "Modelagem Matemática 2" estão inseridas nos planos de ensino disponíveis online para o curso de Licenciatura em Matemática. Além do mais

A Universidade Estadual de Campinas IMECC/UNICAMP deu um primeiro passo
para transformar o problema da formação do professor de matemática, ao implantar
a disciplina "Modelos Matemáticos" no programa de Licenciatura em Matemática

${ }^{1}$ Disponível em: <http://www.utfpr.edu.br/estrutura-universitaria/pro-reitorias/prograd/catalogo-de-cursos-dautfpr/toledo/licenciatura-em-matematica>. Acesso em: 26 mar. 2012. 


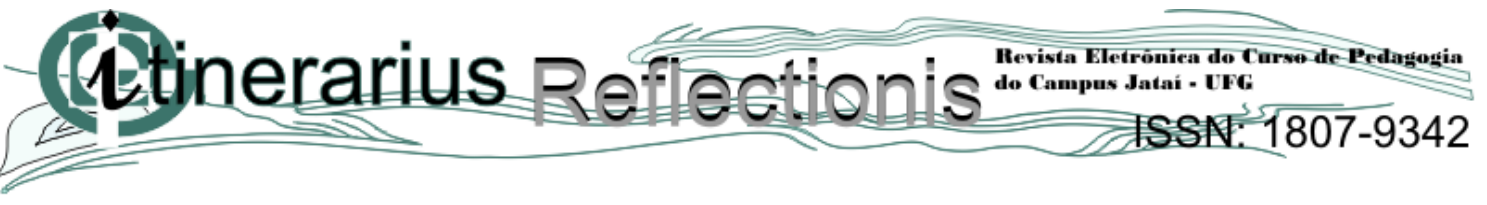

(vespertino) esse programa foi aplicado com sucesso em algumas turmas do programa de licenciatura (1995 - 1997), (BASSANEZI, 2010, p.181).

A implantação da modelagem matemática nas universidades contribuirá na formação do professor criando uma ideologia de como trabalhar a técnica em sala de aula proporcionando desenvolvimento de suas habilidades, seu senso crítico, tornando-se mais dinâmico na aplicação em suas aulas.

Por outro lado, espera-se que o professor ao concluir seu curso de licenciatura encontra-se motivado, cheios de ideias inovadoras, buscando mudança no meio onde vive, mas se depara com desafios, uma delas, por exemplo, se refere a sua remuneração, pois a classe não é valorizada como deveria devido à tamanha responsabilidade que possui perante a sociedade. Vale lembrar que o professor trabalha na formação do ser humano pensante e crítico. Contudo, não é difícil de encontrar exemplos do descaso com o profissional da educação. O piso salarial, por exemplo, estipulado pelo Governo Federal, disponível no portal $\mathrm{R} 7^{2}$, é de $\mathrm{R} \$ 1.451,00$ para uma carga de 40h semanais, a ser prevalecido a partir de janeiro 2012. Se isso não fosse suficiente para desmotivar a classe trabalhadora dos professores, pode-se verificar a existência de inúmeros outros cargos públicos que nem cursos superiores exigem e com salários bem mais generosos. Um exemplo recente é o concurso do Senado Federal3 de 2012. Lá se encontram cargos que a exigência para assumi-lo é de possuir apenas nível médio e os salários ultrapassam os $\mathrm{R} \$ 13.000,00$.

Com tantos problemas estruturais, salariais, de gestão e outros, fica muito complicado exigir do professor que durante sua capacitação (neste caso, na graduação em licenciatura) que o mesmo seja polivalente ao ponto de se dedicar ao máximo. O que acontece na maioria dos casos é que o estudante de licenciatura vai 'empurrando com a barriga' o quanto pode criando desta forma um profissional mal qualificado para o mercado de trabalho.

Fica claro nos exemplos citados acima iniciativas isoladas de se inserir modelagem matemática nos cursos de licenciaturas bem como alternativas similares numa tentativa de qualificar melhor os profissionais desta área, porém algo é certo, se o Governo Federal, os Governos Estaduais e Municipais não se unirem para melhorar a remuneração destes profissionais, todas as tentativas de melhorar esses cursos e consequentemente os

\footnotetext{
${ }^{2}$ Disponível em: <http://noticias.r7.com/vestibular-e-concursos/noticias/mec-divulga-novo-piso-salarial-paraprofessores-20120227.html>. Acesso em: 26 mar. 2012.

${ }^{3}$ Disponível em: <www.fgv.br/fgvprojetos/concursos/senado11> Acesso em: Acesso em: 12 fev. 2012.
} 


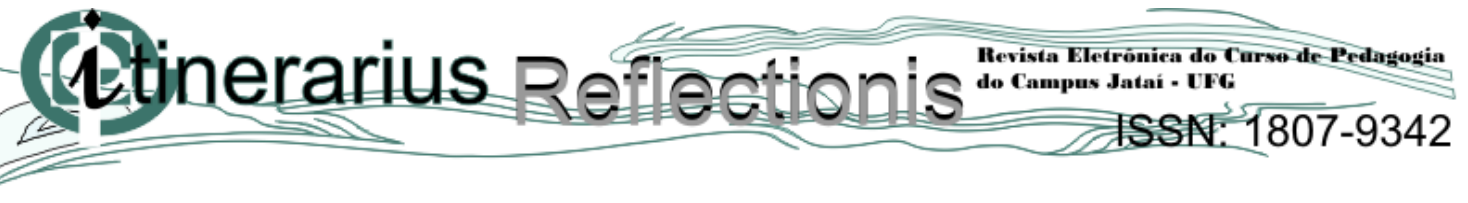

futuros professores, mesmo que bem sucedidas, jamais alcançarão seu ápice, pois sempre haverá profissionais insatisfeitos com o que recebem, encarando a educação como um 'bico'.

\section{ESCOLHA DE UM TEMA PARA APLICAÇÃO DE MODELAGEM MATEMÁTICA E FUNÇÕES}

Procurou-se eleger um tema que poderia ser trabalhado paralelamente com outra disciplina. Além disso, deveria ser um assunto bastante difundido nas mídias atuais e que pudesse ser representado de forma simples num contexto matemático. Surgiu a ideia de se trabalhar com o lixo, pois se trata de assunto bem divulgado nos principais meios de comunicações e revistas de grande circulação no país. Além disso, tratava-se de um tema em que o professor de geografia da turma se propôs a trabalhar acerca deste assunto. Este talvez foi principal motivo da escolha deste tema, já que houve a sonhada interdisciplinaridade que é sempre muito solicitada pelos teóricos da educação. O tema reciclagem (lixo) foi trabalhado paralelamente aos conteúdos da grade curricular de geografia, a partir do início do $3^{\circ}$ Bimestre, por meio de vídeos, atividades extraclasses, exposição oral e cartazes na Escola inserida nesta pesquisa. Foram utilizadas aproximadamente dez aulas para execução destas atividades.

A primeira atividade proposta na aula de matemática envolvendo reciclagem, já que este tema também foi trabalhado em aulas de geografia, foi justamente verificar se estes tinham realmente alcançado o objetivo nas aulas de geografia, isto é, se ambos os alunos tinham se familiarizado com este tema. Para tanto, foi sugerido atividades de fixação sobre o tema reciclagem envolvendo especificadamente o lixo. As apresentações das atividades, cerca de 10 dias depois de solicitado, aconteceram por meio de vídeos, rodadas de discussões na sala de aula ou de outras formas que melhor se adaptassem a realidade de cada aluno envolvido neste processo. Vale ressaltar que durante este intervalo de tempo, as aulas de matemática continuaram normalmente, seguindo a matriz curricular. Diante da diversidade de informações apresentadas pelos alunos, percebeu-se que estes já tinham se familiarizado com o assunto e que o objetivo inicial em que os alunos deveriam aprender sobre o tema reciclagem nas aulas de geografia foi alcançado. Isto foi muito importante, já que para modelar determinado problema deve-se naturalmente saber detalhes sobre o tema proposto.

Em relação à escolha do conteúdo de funções, este também não foi aleatório. A origem da noção de "função" até os conceitos que se tem hoje foi um processo longo e 


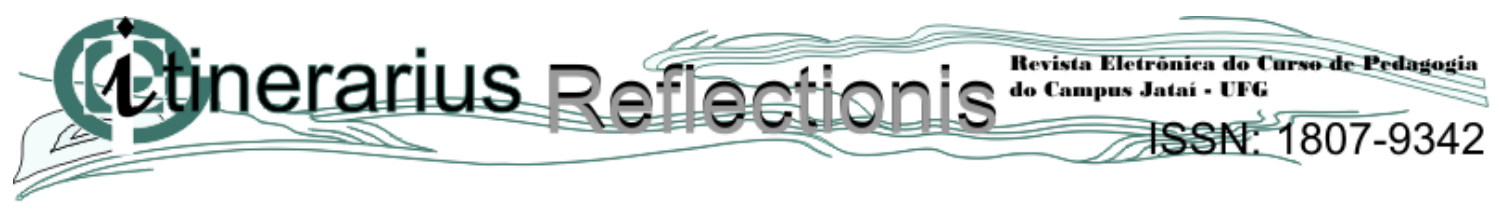

delicado. Demoraram-se vários séculos até que de fato conseguiu-se obter conceitos aceitáveis. Somente no início do século XX passou-se a ter uma definição admissível. Em tempos contemporâneos, por exemplo,

\begin{abstract}
Uma função $f: A \rightarrow B$ consta de três partes: um conjunto $A$, chamado o domínio da função (ou o conjunto onde a função é definida), um conjunto $B$, chamado o contradomínio da função, ou o conjunto onde a função toma valores, e uma regra que permite associar, de modo bem determinado, a cada elemento $x \in A$, um único elemento $f(x) \in B$, chamado o valor a função assume em $x$ (ou no ponto $x$ ). Usa-se a notação $x \rightarrow f(x)$ para indicar que $f$ faz corresponder a $x$ o valor $f(x)$, (LIMA, 2002, p. 10).
\end{abstract}

$\mathrm{Na}$ atualidade, as funções podem ser aplicadas e relacionadas em todas as ciências, por exemplo, na física, química, biologia e outras. É excelente ferramenta de solucionar e representar questões atuais, simular graficamente uma situação problema como, por exemplo, obter uma Função Custo, Receita ou lucro. Isto a torna uma importante ferramenta para modelar situações encontradas no cotidiano, pois sua aplicação no campo da matemática e em outras ciências é vasta.

Estas aplicações, na maioria das vezes, são obtidas por meio da modelagem matemática. Portanto, o estudo de funções atreladas a aplicações, pode "propiciar aos alunos uma abordagem mais significativa e contextualizada”, (BRASIL, 1997, p. 44). Além disso, o estudo de funções,

permite ao aluno adquirir a linguagem algébrica como a linguagem das ciências, necessária para expressar a relação entre grandezas e modelar situações problemas, construindo modelos descritivos de fenômenos e permitindo várias conexões dentro e fora da matemática, (BRASIL, 2002, p.121).

Por outro lado, como o conteúdo de funções é naturalmente apresentado e discutido pelo professor no $9^{\circ}$ ano (detalhes acerca da escolha da turma será apresentado na seção Justificativa da Escolha da Turma), já que este é parte da matriz curricular destes alunos, ficava mais fácil uma assimilação maior dos alunos por parte deste conteúdo. Entretanto, sucessivas revisões acerca de funções foram sendo realizadas paralelamente aos outros conteúdos da grade curricular. Estas revisões foram acontecendo desde o início no $2^{\circ}$ bimestre, prolongando-se até meados do $3^{\circ}$ bimestre num total de aproximadamente quinze aulas, isto é, aproximadamente de um mês e meio. A revisão baseou-se principalmente em funções de $1^{\circ}$ grau e técnicas para soluções de sistemas e equações de $1^{\circ}$ grau. Em seguida, já no quarto Bimestre, foram trabalhados conceitos necessários para se utilizar as técnicas de modelagem matemática nas resoluções de problemas reais por meio de funções e resolução de 


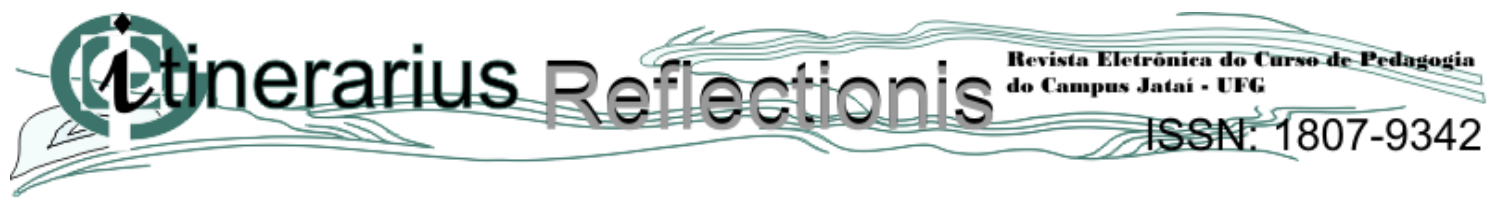

equações de $1^{\circ}$ grau envolvendo reciclagem, principalmente sobre o tema lixo que é um dos grandes gargalos da atualidade. Além disso, foram discutidos conceitos de como construir tabelas, fazer a leitura de gráficos e identificação de varáveis. Além disso, foram apresentados alguns problemas, tais como problemas resolvidos em matemática e na física com utilização modelagem de funções do primeiro grau. Neste caso, foram apresentadas algumas situações problemas para que todos os alunos envolvidos neste processo resolvessem os exercícios apresentados. Discussões acerca de modelagem matemática duraram aproximadamente oito aulas, sendo estas trabalhadas paralelamente ao conteúdo da grade curricular dos alunos. Vale destacar que o conhecimento adquirido sobre reciclagem (lixo), nas aulas de Geografia, foi muito importante neste momento, propiciando maior rapidez na aplicação desta técnica. Mais detalhes acerca das atividades propostas envolvendo reciclagem serão abordados na seção Situações Problemas.

\section{JUSTIFICATIVA DA ESCOLHA DA TURMA}

A proposta de aplicar modelagem matemática foi executada em uma escola do município de Rio Verde - GO, zona rural, aproximadamente $60 \mathrm{~km}$ do centro do município. Para aplicação da modelagem matemática, escolhe-se a turma do $9^{\circ}$ ano. Esta escolha não foi aleatória e alguns critérios tiveram que ser cuidadosamente considerados.

O primeiro critério utilizado estava relacionado ao fato de que os discentes envolvidos nesta pesquisa deveriam possuir um maior conhecimento no ensino de matemática. Pois havia necessidades específicas, como interpretação de problemas e maior conhecimento matemático. Portanto, dentre as turmas do $6^{\circ}$ ao $9^{\circ}$ ano, subtendem-se que o $9^{\circ}$ ano possui melhor desempenho neste quesito por possuírem uma bagagem maior em relação aos conteúdos da Matemática.

Em seguida, foi feito um levantamento de dados em relação à frequência dos alunos para poder acompanhar assiduidade destes. A tabela 1 mostra que o $9^{\circ}$ ano apresentava um dos menores índices de faltas, isto é, $25 \%$. Portanto, em tese seria a turma com maior assiduidade e isto facilitaria a aplicação da metodologia.

Tabela 1 - Número total de faltas dos alunos do $1^{\circ} \mathrm{e} 2^{\circ}$ bimestres.

\begin{tabular}{c|c|c|c}
\hline Ano & $\mathbf{N}^{\mathbf{0}}$ de alunos & Faltas & Percentual Total de Faltas \\
\hline $6^{\circ}$ & 17 & 93 & $46,5 \%$ \\
\hline $7^{\circ}$ & 20 & 92 & $46 \%$ \\
\hline $8^{\circ}$ & 22 & 50 & $25 \%$ \\
\hline
\end{tabular}




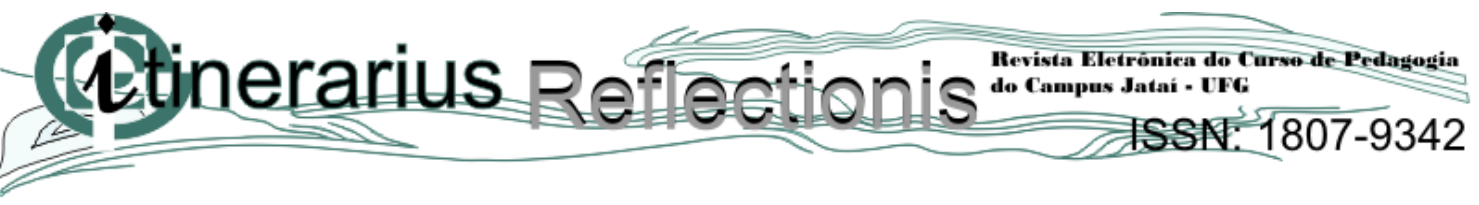

\section{\begin{tabular}{l|r|r}
$9^{\circ}$ & 24 & 50
\end{tabular}}

$25 \%$

Fonte: Secretaria Municipal de Educação de Rio Verde - GO.

Terceiro, de acordo com Tabela 2, a turma com menor índice de evasão era a turma do $9^{\circ}$ ano com $29 \%$ de alunos evadidos e/ou transferidos. Importante destacar que desde o princípio foi explicitado que todos os alunos que iniciassem este projeto deveriam permanecer neste até o final da aplicação da técnica, com o objetivo de coletar a maior quantidade de dados possíveis e, portanto, ter melhor precisão e clareza nos dados coletados.

Tabela 2 - Percentual de alunos evadidos no $1^{\circ}$ e $2^{\circ}$ bimestres.

\begin{tabular}{c|c|c|c|}
\hline Ano & $\mathbf{N}^{\mathbf{0}}$ de alunos & $\begin{array}{l}\text { Alunos Evadidos e } \\
\text { Transferidos }\end{array}$ & $\begin{array}{l}\text { Percentual de Alunos } \\
\text { Evadidos e Transferidos }\end{array}$ \\
\hline $6^{\circ}$ & 17 & 07 & $41 \%$ \\
\hline $7^{\circ}$ & 20 & 09 & $45 \%$ \\
\hline $8^{\circ}$ & 22 & 07 & $31 \%$ \\
\hline $9^{\circ}$ & 24 & 07 & $29 \%$ \\
\hline
\end{tabular}

Fonte: Secretaria Municipal de Educação de Rio Verde - GO.

Assim, com os critérios descritos acima, justifica-se a escolha da turma do $9^{\circ}$ ano para aplicação da metodologia já citada anteriormente. É importante salientar que após uma consulta verbal aos alunos do $9^{\circ}$ ano, os mesmos foram enfáticos em dizer que nunca haviam trabalhado com a técnica de modelagem matemática e não sabiam dizer o que significava.

As atividades foram aplicadas seguindo as etapas sugeridas por Bienbengut \& Hein (2010). Além disso, as aulas foram elaboradas levando-se em consideração as etapas de um plano de aula normal com objetivos, metodologia, recursos didáticos a serem usados.

\section{SITUAÇÕES PROBLEMAS}

A ideia nesta etapa, num contexto prático, foi fazer com que os alunos se interessassem pelo objeto de pesquisa. Como Reciclagem (lixo) é um tema da atualidade, esperava-se que todos comentassem e interagissem com perguntas e/ou outras participações, pois além de atual, este é bem difundido nos meios de comunicação. Como já mencionado na seção Escolha de um Tema para Aplicação de Modelagem Matemática e Funções, os estudos para aplicação desta técnica ocorreram em conformidade com o Quadro 1.

Quadro 1 - Estudos e Revisões elaborados para estudo de funções, modelagem e reciclagem.

\begin{tabular}{|l|c|c|}
\hline \multicolumn{1}{|c|}{ Estudos e/ou Revisão } & Total de Aulas (Máximo) & Interdisciplinaridade \\
\hline Reciclagem (lixo) & 10 & Geografia \\
\hline
\end{tabular}




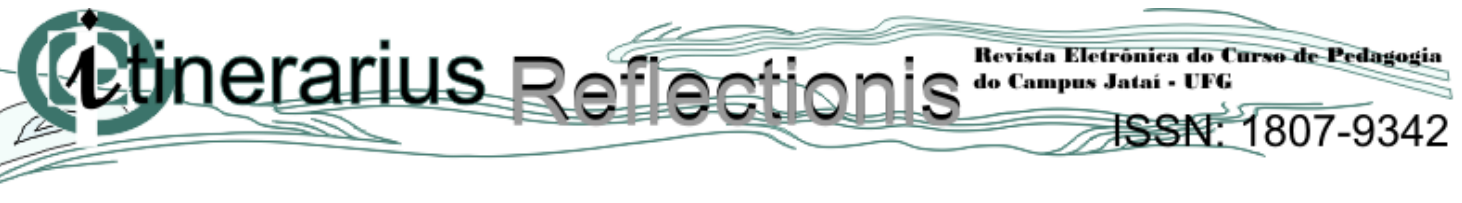

\begin{tabular}{|l|l|l|}
\hline Funções & 15 & Não houve \\
\hline Modelagem & 10 & Geografia \\
\hline
\end{tabular}

Fonte: Elaboração própria, oriundos a partir de dados da pesquisa.

Dentre as atividades programadas de revisão no que tange funções, reciclagem e estudos sobre modelagem foi solicitado aos alunos, em linhas gerais, que pesquisassem os seguintes dados para que estes auxiliassem na construção do modelo matemático:

- Qual o destino do lixo produzido por uma cidade? (neste caso foi sugerido que pesquisassem as cidades de Rio Verde - GO, Goiânia - GO e Brasília - DF).

- O lixo é reciclado?

- Qual a quantidade de lixo produzido por uma pessoa em um dia?

- Se considerarmos uma cidade com determinada população, quais os tipos de lixos que são produzidos? É viável reciclar? Quais as vantagens? Qual o tempo de decomposição de certos materiais, como vidro, plástico e o papel?

Esta etapa da pesquisa foi importante, pois se procurou seguir as etapas e subetapas propostas por Bienbengut \& Hein (2010), e a interação, era a primeira delas, isto é, reconhecimento da situação-problema e familiarização com o assunto a ser modelado. Neste passo foi destacada a importância de se reciclar, se é viável ou não, ou se for o caso, por qual motivo não fazer a reciclagem. Vale lembrar que a modelagem e reciclagem foram trabalhadas paralelamente aos conteúdos da grade curricular em parceria com aulas de Geografia. Neste caso, em específico, pesquisas sobre o assunto estudado (reciclagem), como já frisado anteriormente, tiveram que ser executadas extraclasses. Um problema encontrado nesta etapa se refere ao fato de que a escola que está sendo executada esta atividade é uma escola de zona rural e de difícil acesso, com sala de informática, porém sem internet.

Por se tratar de assunto muito importante e corriqueiro na vida dos alunos, foi perceptível claramente que tal situação estimulou muitos questionamentos dos alunos, demonstrando um interesse satisfatório, acima do normal. Com isso, abriu-se a possibilidade de explorar vários assuntos relacionados ao tema.

Na próxima etapa, "matematização", foi posto em prática o conhecimento teórico de funções, pois era necessário identificar todas as variáveis envolvidas no processo, uma vez que como destaca Bienbengut \& Hein (2010, p. 13), é necessário a "formalização do problema" e a "resolução do problema em termos do modelo". Para tanto, foi utilizado o 


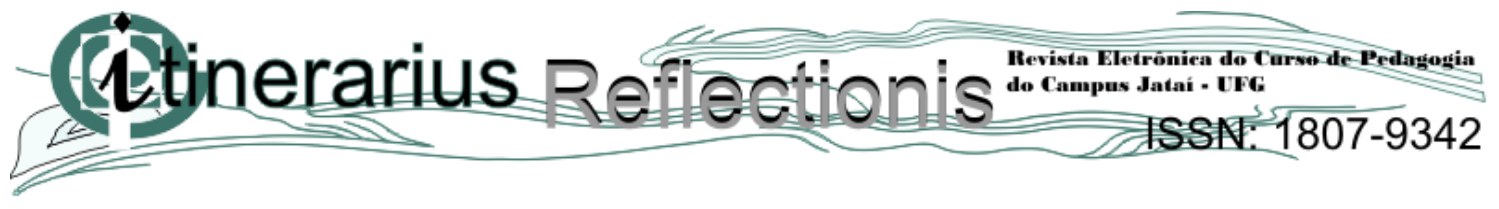

conceito elementar de função do $1^{\circ}$ grau ou função afim, ou seja, $f(x)=a x+b$. Este é claro, cuidadosamente revisado em concordância com a Quadro 1.

Especificamente, como mostra a Quadro 2, foi sugerido aos alunos questões que envolviam o tema reciclagem, baseadas em questões corriqueiras que os alunos podem facilmente se deparar no seu cotidiano, tanto na escola, em sua casa, ou até mesmo presenciálos nos meios de comunicação. São elas:

Quadro 2 - Questões propostas em sala de aula sobre o tema reciclagem.

\begin{tabular}{|c|l|}
\hline Item & \multicolumn{1}{|c|}{ Questões Propostas } \\
\hline 1 & $\begin{array}{l}\text { Se cada aluno conseguir recolher das ruas em média 10 kg por dia de lixo, quantos } \\
\text { quilos conseguirá recolher em: a) Uma semana; b) Um mês; c) Um trimestre; d) Um } \\
\text { semestre; e) Um ano. }\end{array}$ \\
\hline 2 & $\begin{array}{l}\text { Sabe-se que na cidade o quilo do papel é vendido a R\$ 0,18. Se cada um de vocês } \\
\text { por dia conseguir juntar 3 kg de papel durante o mês de janeiro, quanto vocês irão } \\
\text { receber pela venda papel? }\end{array}$ \\
\hline 3 & $\begin{array}{l}\text { Segundo fontes da "abrelpe" 4 o nosso País produz atualmente aproximadamente } \\
220 \text { mil toneladas de lixo diariamente. Diante disso, quantas toneladas o país } \\
\text { produziria em: a) Uma semana; b) Uma quinzena; c) Um mês. }\end{array}$ \\
\hline 4 & $\begin{array}{l}\text { Segundo Regina (2006), "50 quilos de papel usado transformado em papel novo } \\
\text { evita que uma arvore seja cortada". Reflita na quantidade de papel que você jogou } \\
\text { fora até a presente data e calcule quantas arvores você deixou de preservar. Se você } \\
\text { jogou fora 200 kg de papel, quantas árvores poderiam ser preservadas? }\end{array}$ \\
\hline 5 & $\begin{array}{l}\text { Qual a quantidade de lixo produzido por uma pessoa diariamente? Em seguida, } \\
\text { analisar quantas pessoas possui sua família e analisar a quantidade de lixo produzido } \\
\text { pela mesma em: a) Uma semana; b) Um mês; c) Uma cidade. }\end{array}$ \\
\hline
\end{tabular}

Fonte: Elaboração própria, a partir de dados oriundos da pesquisa.

Essa ultima questão por sinal está intensamente ligada ao modelo que foi elaborado. Para tanto, cada aluno teve a tarefa de pesquisar, em média, qual a produção de lixo individual por dia de cada cidadão no Brasil. Segundo reportagem publicada no diário do Estadão $^{5}$, este índice é de $1,152 \mathrm{~kg}$ dia. Para encontrar o tal indicador foi feito uma razão entre a população total do país e a quantidade de lixo produzida pelos mesmos. Dados sobre o número de habitantes do Brasil podem ser encontrados no site do Instituto Brasileiro de Geografia e Estatística (IBGE), e segundo estimativas, o Brasil já possui cerca de 192 milhões de habitantes. Usando tais dados, obteve-se a seguinte função $y=1,152 x$. Esta se trata de

\footnotetext{
${ }^{4}$ Disponível em: < http://www.abrelpe.org.br/>. Acesso em 02 jul. 2012

5 Disponível em: <http://www.estadao.com.br/noticias/impresso,brasileiro-produz-tanto-lixo-quantoeuropeu,556731,0.htm>. Acesso: 04 nov. 2011
} 


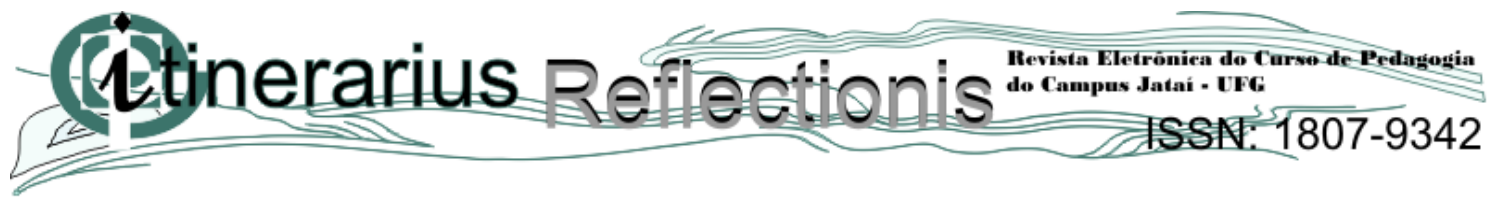

uma função linear de primeiro grau e, portanto, se obtém um modelo para fazer estimativas no que tange a produção de lixo de qualquer cidade do país.

\section{RESULTADOS OBTIDOS}

Na seção Situações Problemas, foram destacados cinco problemas que naquela ocosião se referiu como "questões corriqueiras que os alunos podem facilmente se deparar no seu cotidiano". Executada a aplicação dos cinco problemas propostos, observou-se melhora significativa nos rendimentos dos alunos e isto pode ser obervado no Gráfico 1. De acordo com o Gráfico 1, pode-se afirmar que dos alunos que participaram da pesquisa, $88 \%$ dos destes acertaram todas as questões e $12 \%$ erraram pelo menos uma das questões. Vale destacar que os erros aconteceram no problema 5 e como já comentado anteriormente se trata de uma situação problema em que estava envolvida o modelo em que os alunos deveriam construir.

Outro ponto positivo que foi observado durante esta investigação foi o melhoramento das médias dos discentes envolvidos nesta pesquisa durante o ano letivo de 2011. Isto pode ser observado no Gráfico 2. Observa-se que os alunos possuiam uma média de 6,4 no primeiro bimestre, 6,7 no segundo, 7,2 no terceiro e 7,4 no quarto bimestre. Isto representa um ganho de $15,6 \%$ a mais nas médias se for feita comparação com o primeiro e o quarto bimestre respectivamente. Vale destacar ainda que a implantação da metodologia elencada neste artigo, começa-se a ser empregada já no segundo bimestre e implementada de fato no segundo simestre, que compreende o terceiro e quarto bimestre, e sem dúvida este fato, ou seja, a mudança de rotima implementada na sala de aula já proporciounou alguma mudança, já que as médias saltaram de 6,4 no primeiro para 6,7 no segundo bimestre, o que representa um ganho de $4,6 \%$.

Gráfico 1 - Percentual de acertos e erros dos alunos que responderam as questões propostas. 

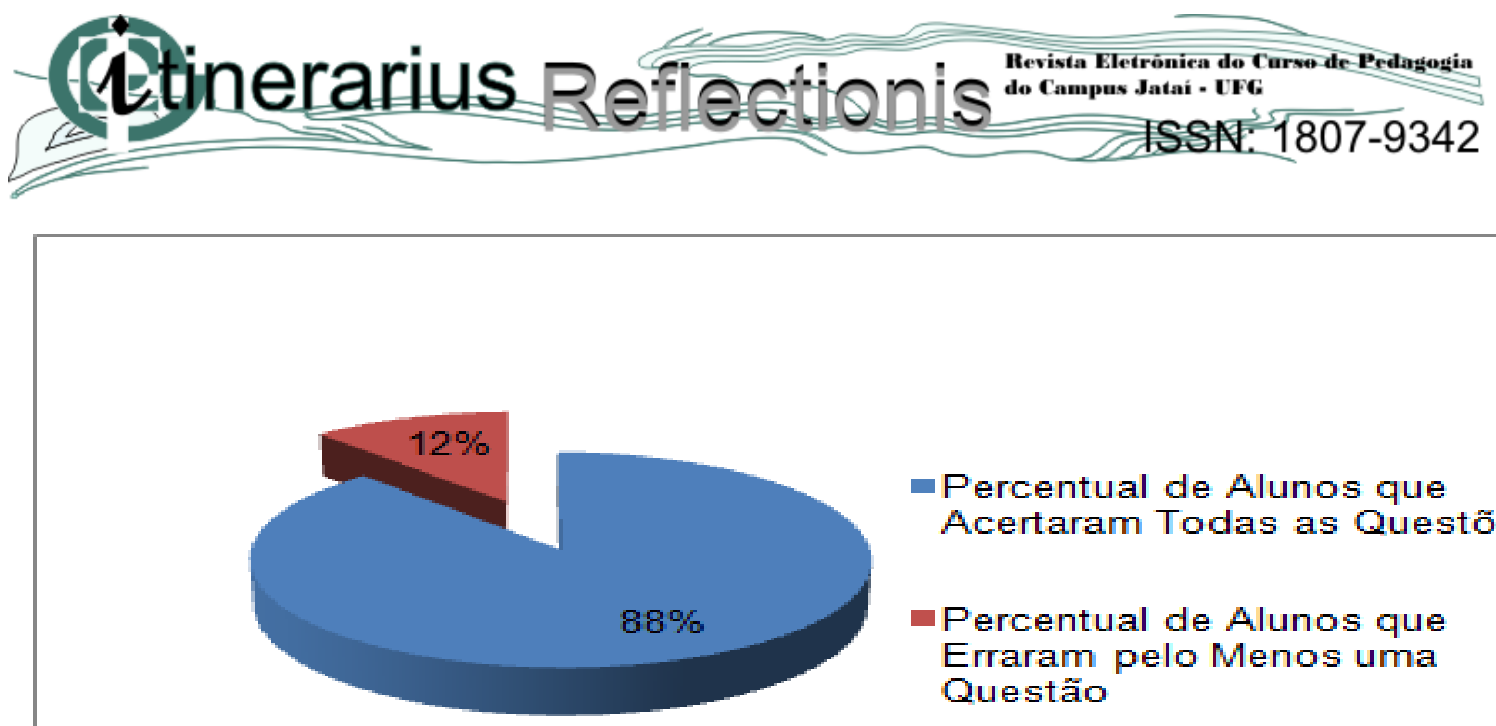

- Percentual de Alunos que Acertaram Todas as Questões

- Percentual de Alunos que Erraram pelo Menos uma Questão

Fonte: Elaboração própria, a partir de dados oriundos da pesquisa.

Observe no Gráfico 2 que a tendência das médias de certa forma aproxima-se de uma reta. Isto pode ser observado no Gráfico 2. Neste gráfico, através de um pouco de álgebra se obtém uma função $y=0,35 x+6,05$ que é obtido através da Interpolação Linear ${ }^{6}$ das médias dos quatro bimestres já citados anteriormente.

Gráfico 2 - Médias das notas bimestrais - 2011.

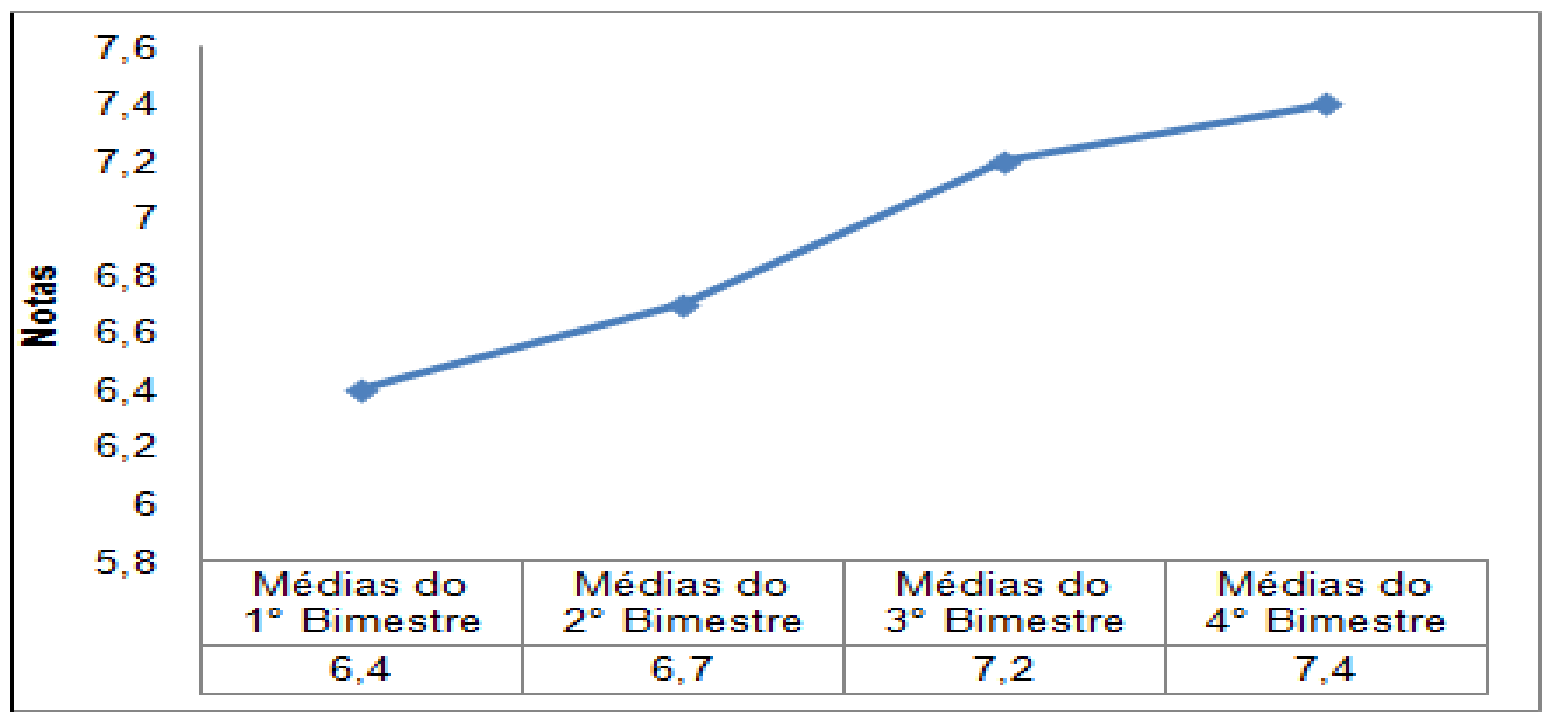

Fonte: Secretaria Municipal de Educação de Rio Verde - GO.

É importante salientar que se a tendência for mantida, pode-se predizer, por exemplo, em quantos bimestres a média destes alunos se aproximaria de 9,0. De fato, se a convergência for mantida, fazendo $y=9$ na equação $y=0,35 x+6,05$, obtem-se $x \cong 8,5$,

\footnotetext{
${ }^{6}$ Mais explicações acerca da Interpolação Linear podem ser encontradas em: Barroso et al, Cálculo numérico com aplicações, $2^{\text {a }}$ Ed. pág. 151.
} 


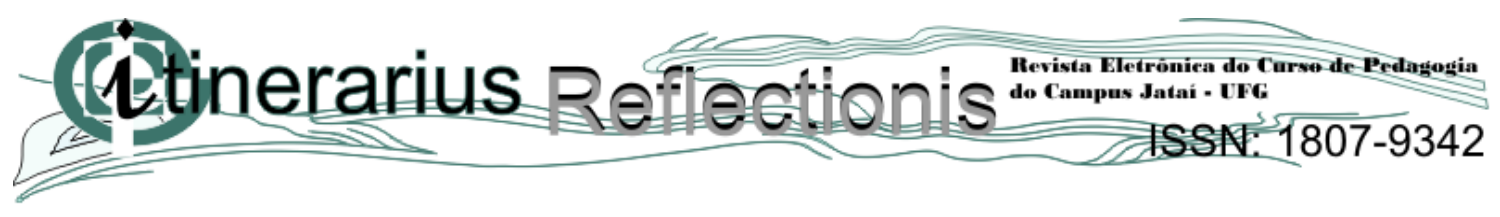

ou seja, em mais quatro bimestres e meio a média da turma seria de 9,0, o que certamente seria extraordinário. Vale ressaltar que isto é apenas uma estatística do que pode vir a acontecer, não significando que de fato ocorrerá.

Gráfico 3 - Linearização das médias do $1^{\circ}, 2^{\circ}, 3^{\circ}$ e $4^{\circ}$ bimestres.

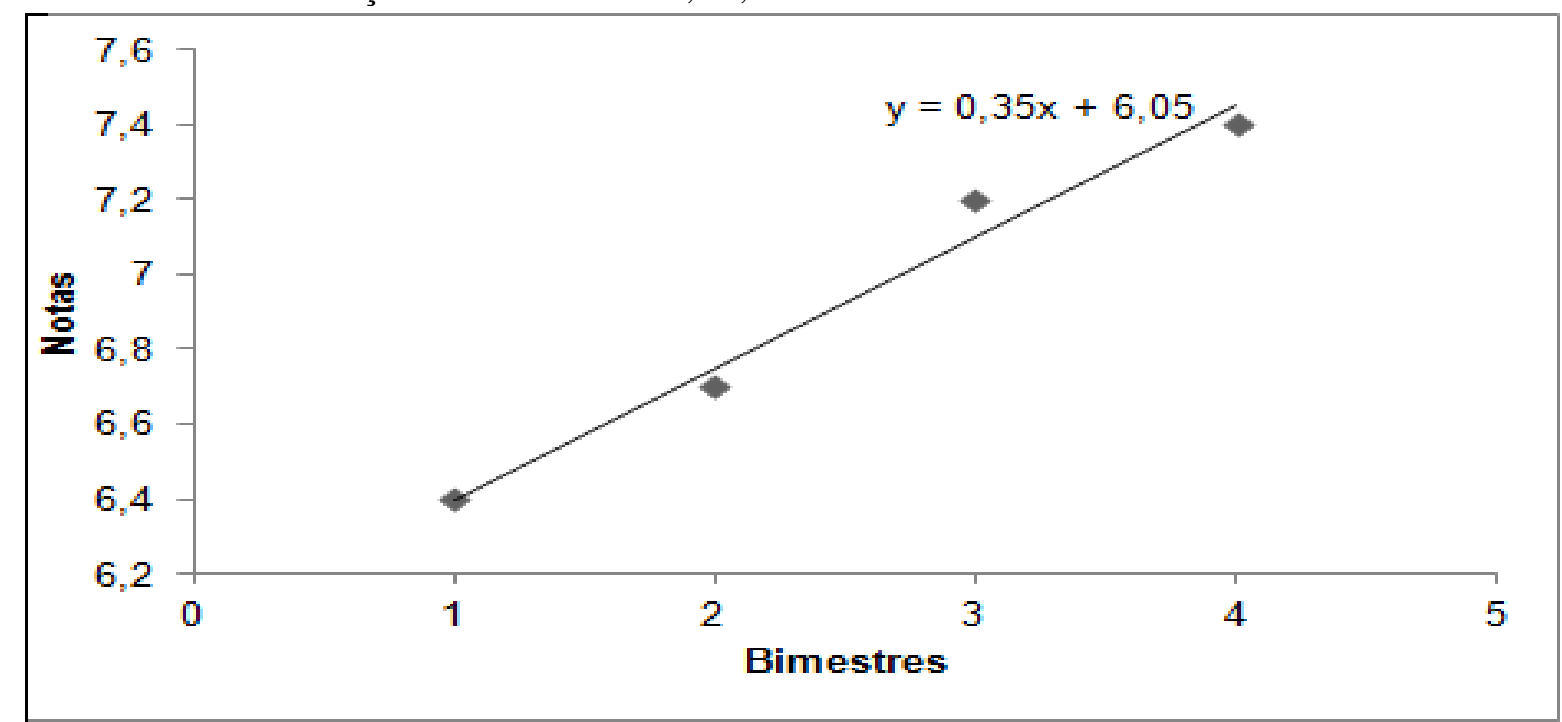

Fonte: Elaboração própria, a partir de dados oriundos da pesquisa.

Por fim, outro dado muito importante, foi à diminuição das faltas dos alunos durante ano letivo de 2011. Estes números podem ser observados na Tabela 3.

Tabela 3 - Total de faltas semestrais - 2011 .

\begin{tabular}{c|c|c}
\hline Ano & Total de Faltas do $1^{\circ}$ Semestre & Total de Faltas do $2^{\circ}$ Semestre \\
\hline $9^{\circ}$ & 50 & 15 \\
\hline
\end{tabular}

Fonte: Secretaria Municipal de Educação de Rio Verde - GO.

Observa-se na Tabela 3 que a quantidade de faltas no primeiro semestre, que era de 50, reduziu drasticamente para 15 no segundo semestre quando a metodologia descrita neste artigo foi implantada. Isto representa uma queda de $70 \%$ nas faltas. Isto reforça a tese de que houve comprometimento dos alunos no processo de Ensino e Aprendizagem.

\section{CONSIDERAÇÕES FINAIS}

Deve-se ficar claro que os dados apresentados a seguir podem e devem ser melhorados se a metodologia apresentada neste artigo for executada durante a prática docente não só destes pesquisadores e sim de todos os professores de matemática do Ensino Fundamental e/ou Médio e/ou até mesmo no Ensino Superior. 


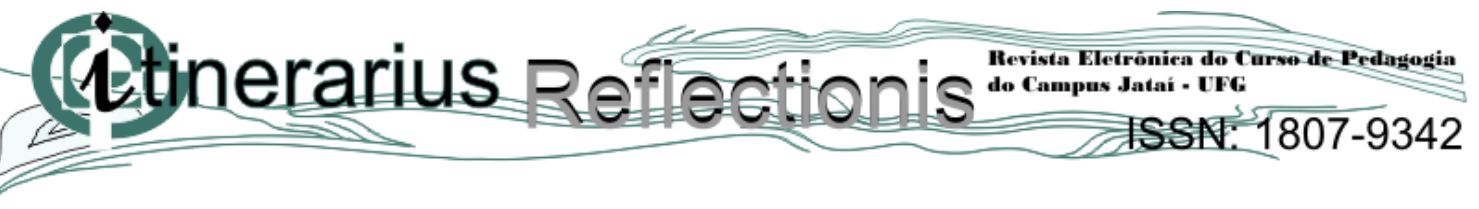

Primeiramente, pode-se observar através do Gráfico 1 o alto índice de acertos nas atividades propostas, $88 \%$ de acertos e $12 \%$ de erros, o que não é normal em matemática. Geralmente é o contrário que ocorre. Além disso, o Gráfico 2 mostra que as médias dos alunos que interagiram com o a metodologia também aumentou gradativamente o que significa um ganho real de $15,6 \%$ nas médias comparadas do quarto com o primeiro bimestre daquele ano. Outro dado importante que deve ser destacado encontra-se na Tabela 3. Lá fica claro que esta metodologia de certa forma influenciou os alunos a permanecerem mais na sala de aula e principalmente a gostarem de assistir as aulas de matemática, já que o índice de faltas diminuiu muito do primeiro para o segundo semestre do ano de 2011 , cerca de $70 \%$.

Portanto, pode-se afirmar que a modelagem matemática como metodologia de ensino mostrou-se eficaz no processo de ensino-aprendizagem de matemática, mais especificadamente no estudo de funções e outros conteúdos podem ser estudados com o auxilio desta técnica, cabe ao professor ou educador se disponibilizar para efetuar tal tarefa.

É importante destacar que ações desta magnitude sempre são bem vistas pela sociedade escolar e em geral apresentam bons resultados. Por outro lado, isto é apenas uma ação isolada e muito pouco significa se comparada aos dados alarmantes que apresentam a educação deste país. Portanto, é muito importante que os professores sejam mais valorizados e que uma política pública de reestruturação da educação deste país seja implantada imediatamente para que no futuro se possa colher os frutos e ter uma educação exemplar e de qualidade.

\section{REFERÊNCIAS}

BARBOSA, Jonei Cerqueira. Modelagem Matemática e os Futuros Professores. In: REUNIÃO ANUAL DA ANPED, Caxambu - SC, n. 25, p.1-11, 29 set. 2002. Anual. Disponível em: <http://www.anped.org.br/reunioes/25/texced251.htm\#gt19>. Acesso em: 24 jun. 2013.

BASSANEZI, Rodney Carlos. Ensino-aprendizagem com modelagem matemática: uma nova estratégia. $3^{\text {a }}$ Edição São Paulo: Contexto, 2010. 389 p. $2^{\mathrm{a}}$ Reimpressão.

BIEMBENGUT, Maria Salett; HEIN, Nelson. Modelagem matemática no ensino no ensino. $5^{\text {a }}$ ed. São Paulo: Contexto, 2010. 127 p. $1^{\text {a }}$ Reimpressão.

BRASIL. Ministério da Educação. PCN+ Ensino Médio: Orientações Educacionais Complementares aos Parâmetros Curriculares Nacionais. 2002. Disponível em: <http://portal.mec.gov.br/seb/arquivos/pdf/CienciasNatureza.pdf>. Acesso em: 17 jun. 2013. 


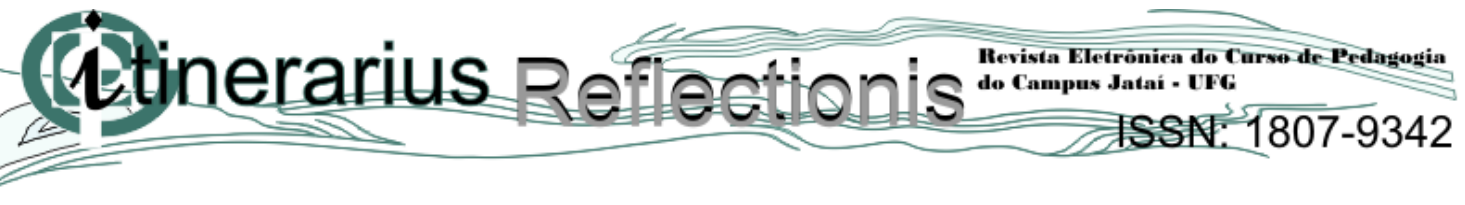

Ministério da Educação. Secretaria da Educação Básica. Orientações Curriculares para o Ensino Médio: Ciências da Natureza, Matemática e suas Tecnologias. 2006.

Disponível em: 〈http://portal.mec.gov.br/seb/arquivos/pdf/book_volume_01_internet.pdf>. Acesso em: 13 jun. 2013

Ministério da Educação. Secretaria de Educação Fundamental. Parâmetros Curriculares Nacionais: introdução aos parâmetros curriculares nacionais. 1997. Disponível em: 〈http://portal.mec.gov.br/seb/arquivos/pdf/livro01.pdf>. Acesso em: 17 jun. 2013.

GIL, Antonio Carlos. Métodos e técnicas de pesquisa social. 5 Edição São Paulo: Atlas, 1999. $206 \mathrm{p}$.

LIMA, Elon Lajes. Curso de Análise, vol. 1, Rio de Janeiro: Instituto de Matemática Pura e Aplicada (Projeto Euclides), 2002. 431 p.

MENEZES, Luiz Carlos de. Como o professor vê a educação. Revista Nova Escola. São Paulo, p.35: Novembro, 2007.

OLIVEIRA, Andreia Maria Pereira de. Como Trabalhar Modelagem Matemática na Formação de Professores? 2007. Disponível em:

<http://www.sbem.com.br/files/ix_enem/Minicurso/Trabalhos/MC74390627520T.doc>. Acesso em: 24 jun. 2013.

PÓLYA, George. A arte de resolver problemas: um novo aspecto do método matemático. Rio de Janeiro: Intercência Ltda, 1995. 196 p. Tradução e adaptação de Heitor Lisboa de Araújo, $2^{\text {a }}$ Reimpressão. Disponível em:

<http://www.mat.ufmg.br/ michel/inicmat2010/livros/polya.pdf>. Acesso em: 25 jun. 2013.

PONTE, João Pedro da. Estudos de Caso em Educação Matemática. Bolema: Boletim de Educação Matemática, São Paulo, v. 19, n. 25, p.1-23, 2006. Semestral. Disponível em: <http://www.periodicos.rc.biblioteca.unesp.br/index.php/bolema/article/view/1880/1657>. Acesso em: 22 jun. 2013.

SILVA, Clovis Antonio da; JAFELICE, Rosana Sueli da Motta. Modelagem como estratégia de ensino-aprendizagem de matrizes, determinantes e sistemas lineares. Famat em Revista: Revista Científica Eletrônica da Faculdade de Matemática - FAMAT Universidade Federal de Uberlândia - UFU - MG, Uberlândia - MG, n. 4, p.255-265, abr. 2005. Disponível em:

<http://www.portal.famat.ufu.br/sites/famat.ufu.br/files/Anexos/Bookpage/Famat_Revista_04 .pdf>. Acesso em: 24 jun. 2013.

REGINA, Silvia. 7 razões para reciclar: Conheça bons motivos para fazer a coleta seletiva de lixo na sua casa. 2006. Disponível em:

<http://planetasustentavel.abril.com.br/noticia/lixo/conteudo_222006.shtml>. Acesso em: 25 jun. 2013. 


\section{(ctinerarius

SILVEIRA, Jean Carlos; RIBAS, João Luiz Domingues. Discussões Sobre Modelagem Matemática e o Ensino-Aprendizagem. 2004. Disponível em:

<http://www.somatematica.com.br/artigos/a8/p2.php>. Acesso em: 14 jun. 2013.

WERNECK, Hamilton. Ensinamos demais Aprendemos de Menos. 10. ed. Petrópolis - RJ: Vozes, 1987. $112 \mathrm{p}$. 